\title{
Commentary: When does the early death risk become constant after a mitral valve operation?
}

\author{
W. Randolph Chitwood, Jr, MD, FACS, FRCS (Eng)
}

\author{
From the Department of Cardiovascular Sciences, Brody School of Medicine East Carolina University, Green- \\ ville, NC. \\ Disclosures: Author has nothing to disclose with regard to commercial support. \\ Received for publication Aug 24, 2019; revisions received Aug 24, 2019; accepted for publication Aug 26, 2019; \\ available ahead of print Oct 18, 2019. \\ Address for reprints: W. Randolph Chitwood, Jr, MD, FACS, FRCS (Eng), 146 E Longmeadow Rd, Greenville, \\ NC 27858 (E-mail: chitwoodw@ecu.edu). \\ J Thorac Cardiovasc Surg 2020;159:e177-8 \\ $0022-5223 / \$ 36.00$ \\ Copyright (c) 2019 by The American Association for Thoracic Surgery \\ https://doi.org/10.1016/j.jtcvs.2019.08.086
}

For many years, we have known that a mitral valve repair (MVP) for degenerative mitral valve disease carries proven excellent long-term survival and freedom from recurrent insufficiency. ${ }^{1-4}$ Repair results in patients with ischemic or cardiomyopathic functional mitral regurgitation, however, have been inferior. ${ }^{5-7}$ In addition, survival with MVP is significantly better than with mitral valve replacement (MVR), even when the chordae tendineae are preserved. $^{8}$ These and other studies have centered on long-term results and not on the early period after a repair or replacement.

In their article in this issue of the Journal, Mori and coauthors ${ }^{9}$ focus on the early (1-year) mortality after successful mitral valve operations done at a single center. They retrospectively reviewed the clinical results of 1048 patients who underwent either MVP ( $\mathrm{n}=624 ; 64.7 \%$ with isolated MVP) or replacement $\left(n=424 ; 50 \%\right.$ with isolated MVR). ${ }^{5}$ Twelve surgeons operated on these patients. There were no in-hospital deaths; however, the 30-day mortalities were $0.2 \%$ and $1.4 \%$ for MVP and MVR, respectively. During this period, survivals were variable between the MVP and MVR groups and were significantly better in the MVP group.

The overall message from the study of Mori and coauthors ${ }^{9}$ is that temporal risk of death after MVP persists for 90 days but stabilizes at a low rate thereafter. In comparison, the mortality risk continues for 180 days after MVR and then stabilizes, but it still remains 2 to 3 times higher than that at the same time point after MVP. Mori and coauthors ${ }^{9}$ have thus shown that early mortality during the first postoperative year persists, but at different rates for MVP and MVR. Potentially confounding their findings, there were many differences between the MVP and MVR cohorts. Both short- and long-term surgical survivals vary widely among patients with myxomatous degeneration, rheumatic disease, ischemic cardiomyopathy, or non-ischemia related dilated cardiomyopathy. Moreover, New York Heart Association heart failure class greatly affects both early and

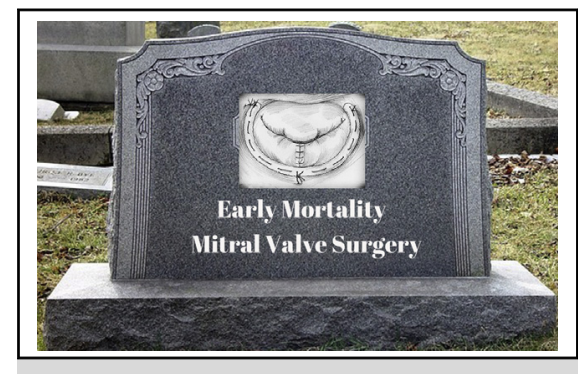

Early mortality happens with mitral surgery—but when?

\section{Central Message}

Variability exists in early postoperative mortality between mitral repair and replacement Mortality from repair is reduced by 90 days, but that from replacement continues, stabilizing after 180 days.

See Article page e171.

late mortality for both MVP and MVR. As expected, the preoperative comorbidities were much higher in the patients studied who underwent MVR. Moreover, only $64.7 \%$ of the patients who underwent MVP and $50 \%$ of those who underwent MVR underwent an isolated mitral valve operation. In addition, $77 \%$ of MVP and $58 \%$ of MVR operations were elective. The two cohorts were thus not optimally comparable because of protean mitral pathology, the significant number of patients not operated on electively, the lack of an isolated mitral valve operation in a significant number of patients, and the lack heart failure consideration. Another point is that the mean patient age was between 64 and 67 years, which excluded the study of older patients who potentially could have had both a higher operative mortality and a higher long-term risk. In addition, the New York Heart Association level of congestive heart failure, which differed between the cohorts, is a predictor of mortality.

Despite these caveats, Mori and coauthors 9 are to be congratulated for providing no operative mortality and a low 30-day mortality in more than 1000 mitral valve operations. This result speaks to the quality of this surgical program in performing mitral valve surgery. It would have been very important if the study could have been done in a population of patients who all underwent isolated mitral operations that were all done electively. Moreover, because repairs can be done safely in patients older than 65 years, expansion of the study would have added useful 
information. Nevertheless, Mori and coauthors ${ }^{9}$ have given us a cogent subjective early risk model of early mortality in these operations. This study and commentary should help guide others when studying the early mortality after mitral valve operations.

\section{References}

1. Gammie JS, Sheng S, Griffith BG, Peterson ED, Rankin JS, O'Brien SM, et al. Trends in mitral valve surgery in the United States: results from the Society of Thoracic Surgeons adult cardiac database. Ann Thorac Surg. 2009;87:1431-9.

2. David TE, Armstrong S, Ivanov JJ. Chordal replacement with polytetrafluoroethylene sutures for mitral valve repair: a 25-year experience. Thorac Cardiovasc Surg. 2013;145:1563-9.

3. DiBardino DJ, ElBardissi AW, McClure RS, Razo-Vasquez OA, Kelly NE, Cohn LH. Four decades of experience with mitral valve repair: analysis of differential indications, technical evolution, and long-term outcome. J Thorac Cardiovasc Surg. 2010;139:76-83; discussion 83-4.
4. Daneshmand MA, Milano CA, Rankin JS, Honeycutt EF, Swaminathan M Shaw LK, et al. Mitral valve repair for degenerative disease: a 20-year experience. Ann Thorac Surg. 2009;88:1828-37.

5. Rankin JS, Grau-Sepulveda M, Shahian DM, Gillinov AM, Suri R, Gammie JS, et al. The impact of mitral disease etiology on operative mortality after mitral valve operations. Ann Thorac Surg. 2018;106:1406-13.

6. Gillinov AM, Blackstone EH, Rajeswaran J, Mawad M, McCarthy PM, Sabik JF III, et al. Ischemic versus degenerative mitral regurgitation: does etiology affect survival? Ann Thorac Surg. 2005;80:811-9; discussion 809.

7. Atluri P, Acker MA. Mitral valve surgery for dilated cardiomyopathy: current status and future roles. Semin Thorac Surg. 2012;24:51-8.

8. Hannan EL, Samadashvili Z, Smith CR, Lahey SJ, Gold JP, Jordan D, et al. Mitral valve repair versus replacement for patients with preserved left ventricular function without heart failure symptoms. J Thorac Cardiovasc Surg. 2019;157: 1432-9.e2.

9. Mori M, Yousef S, Pichert M, Vinholo TF, Geirsson A. Elevated risk of death persists beyond 30 days after mitral valve surgery. J Thorac Cardiovasc Surg. 2020; 159:e171-3. 